\title{
The Risk Of Seizure-Related Hospitalization Among Older Adults On Levetiracetam Monotherapy: A Retrospective Comparative Cohort Study
}

This article was published in the following Dove Press journal:

Neuropsychiatric Disease and Treatment

\author{
Huda Alzahrani ${ }^{1}$ \\ Haya Mohammad Almalag ${ }^{2}$ \\ Yazed AIRuthia (iD) ${ }^{2,3}$ \\ Fawaz Al-hussain (iD) ${ }^{4}$ \\ Bander Balkhi ${ }^{2,3}$ \\ Lama Almutairi ${ }^{1}$ \\ Reem Algasem ${ }^{5}$ \\ Edward B De Vol ${ }^{6}$ \\ Manal Rashed Almarzouqi ${ }^{6}$ \\ Abdulaziz Alsemari iD ${ }^{7}$ \\ 'Department of Pharmacy, King Saud \\ University Medical City, Riyadh, Saudi \\ Arabia; ${ }^{2}$ Department of Clinical \\ Pharmacy, College of Pharmacy, King \\ Saud University, Riyadh, Saudi Arabia; \\ ${ }^{3}$ Pharmacoeconomics Research Unit, \\ College of Pharmacy, King Saud \\ University, Riyadh, Saudi Arabia; \\ ${ }^{4}$ Department of Medicine, Neurology \\ Division, College of Medicine, King Saud \\ University, Riyadh, Saudi Arabia; \\ ${ }^{5}$ Department of Pharmaceutical Care, \\ King Faisal Specialist Hospital and \\ Research Center, Riyadh, Saudi Arabia; \\ ${ }^{6}$ Department of Epidemiology and \\ Scientific Computing, King Faisal \\ Specialist Hospital and Research Centre, \\ Riyadh, Saudi Arabia; ${ }^{7}$ Department of \\ Neurosciences, King Faisal Specialist \\ Hospital and Research Centre, Riyadh, \\ Kingdom of Saudi Arabia
}

Correspondence: Yazed AIRuthia Department of Clinical Pharmacy, College of Pharmacy, King Saud University, Riyadh, Saudi Arabia

Tel +996 II 4677483

Fax +966 II 4677480

Email yazeed@ksu.edu.sa
Background: Antiepileptic drug monotherapy is the mainstay of treatment for epilepsy; however, the efficacy of different antiepileptic drugs in reducing the incidence of seizurerelated hospitalization among older adults, who are at higher risk of developing epilepsy compared to their younger counterparts, has not been examined.

Purpose: The objective of the present study was to compare the rate of seizure-related hospitalization among older adults on levetiracetam compared to different antiepileptic drugs (AEDs).

Patients and methods: This was a retrospective cohort study of older adults ( $\geq 60$ years) in two tertiary care hospitals. Patients who are 60 years of age and older, have a confirmed diagnosis of epilepsy, and are taking a single and the same antiepileptic drug for at least 36 months were included. The patients were followed up for 24 months after 12 months of treatment with no incidence of seizure-related hospitalization via their health records. Multiple Poisson regression with robust error variance was used to estimate the relative risk of hospitalization for patients on levetiracetam compared to different antiepileptic drugs controlling for age, gender, number of prescription medications, dosage strengths, and Charlson Comorbidity Index (CCI) score.

Results: One hundred and thirty-six patients met the inclusion criteria and were included in the study. The recruited patients were on one of the following four antiepileptic drugs: carbamazepine $(n=44)$, levetiracetam $(n=39)$, phenytoin $(n=31)$, and valproic acid $(n=22)$. Patients on levetiracetam were more than twice as likely to be hospitalized due to seizures within the 24 months of follow-up compared to their counterparts on other AEDs $(\mathrm{RR}=2.76$, 95\% CI=1.16-6.53, $P=0.021$ ).

Conclusion: This study suggests that older adults on old generation AEDs such as phenytoin, carbamazepine, and valproic acid appear to have a lower risk of seizure-related hospitalization compared to their counterparts on levetiracetam.

Keywords: seizures, hospitalization, levetiracetam, carbamazepine, phenytoin, valproic acid

\section{Introduction}

Older adults are more likely to develop seizures compared to their younger counterparts. ${ }^{1}$ This can be attributable to a multitude of risk factors that older adults are usually presented with such as stroke, head injuries, and dementia. ${ }^{2-4}$ The incidence of epilepsy is reported to be as high as 60 per 100,000 people in those aged between 40 and 59 years, ${ }^{5}$ though it can be more than 135 per 100,000 
people in those aged 80 years and older. ${ }^{3}$ Additionally, the rate of epilepsy-related mortality is two to three times higher among older adults (e.g., $\geq 60$ years) than their younger counterparts. ${ }^{6}$ The World Health Organization (WHO) estimated that epilepsy may represent $1 \%$ of the global burden of disease since its lifetime prevalence could be as large as 70 million people worldwide. ${ }^{7,8}$ The rates of mortality and hospitalization have increased within the last decade, especially among newly diagnosed patients. ${ }^{9}$ However, age was not found to be associated with healthcare services utilization according to a study that explored the predictors of healthcare resources utilization among a sample of epileptic patients in the United States, ${ }^{10}$ though the cost of healthcare services utilization is believed be significantly higher among older adults with epilepsy than those without epilepsy. ${ }^{11}$

Epilepsy management is largely based on pharmacotherapy. Many antiepileptic drugs (AEDs) used in epilepsy treatment have variable efficacy and safety profiles. ${ }^{12}$ Currently, there are two generations of AEDs. The first generation of AEDs, such as phenobarbital, phenytoin, valproic acid, ethosuximide, and carbamazepine, are still used extensively in the management of epilepsy across different age groups; however, the risk of adverse events is generally higher with those AEDs compared to the second generation of AEDs, such as levetiracetam, lamotrigine, oxcarbazepine, zonisamide, and topiramate. ${ }^{13-16}$ It is known that appropriate selection of an AED can result in effective management of epilepsy and long-term remission shortly after the initiation of treatment, and approximately $70 \%$ of the patients can achieve seizure-freedom with a single AED. ${ }^{17}$ Therefore, different professional organizations, such as the International League against Epilepsy, have published guidelines that assist clinicians in choosing the right AED for their patients. ${ }^{18,19}$

Multiple studies have compared the efficacy and tolerability of several AEDs. Brodie et $a{ }^{20}$ compared the efficacy and tolerability of levetiracetam vs controlledrelease carbamazepine in a sample of adult patients with newly diagnosed focal or generalized tonic-clonic seizures in a randomized, multicenter, double-blind trial. Although the withdrawal rate due to adverse events between the two drugs was higher among patients on carbamazepine, the percentage of patients who achieved seizure-freedom was slightly higher among patients on carbamazepine compared to their counterparts on levetiracetam $(58.5 \%$ vs $56.6 \%) .{ }^{20}$ Similarly, in another multicentre randomized controlled trial that investigated the safety and efficacy of levetiracetam vs sustained-release carbamazepine in a sample of 106 older adults ( $>65$ years) with post-stroke seizure, levetiracetam was non-inferior to carbamazepine in achieving seizure-freedom for 52 weeks, but patients on levetiracetam had a significantly lower rate of adverse events overall compared to patients on carbamazepine. ${ }^{21}$ However, this was not the case with the risk of fracture in which patients on levetiracetam, carbamazepine, or valproic acid had the same risk of fracture after 15 months of follow-up. ${ }^{22}$ Additionally, the new AEDs, such as levetiracetam and lamotrigine, do not appear to lower the rate of adverse events compared to old AEDs, such as phenytoin and carbamazepine, according to another study that compared the self-reported rates of AED adverse events in a sample of older adults. ${ }^{23}$ The SANAD study group has conducted an unblinded randomized clinical trial to compare the efficacy of carbamazepine against lamotrigine, oxcarbazepine, gabapentin, and topiramate for controlling seizures in patients with focal seizures. Lamotrigine was found to be non-inferior to carbamazepine and clinically better than other AEDs in the study for focal seizures. ${ }^{24}$ For generalized and unclassified seizures, the SANAD study group conducted another study to compare the efficacy of valproic acid vs lamotrigine and topiramate for controlling seizures. Although valproic acid was significantly better than topiramate for controlling generalized seizures, it was not better than lamotrigine. ${ }^{25}$ The findings of the SANAD study group's unblinded randomized clinical trials for focal and generalized seizures were confirmed in the latest network meta-analysis by the Cochrane group, which suggests that carbamazepine and lamotrigine should be considered as first-line treatment options for patients with focal seizures while levetiracetam can be considered as an alternative. In contrast, valproic acid and lamotrigine should be considered first-line treatment options for generalized seizures with levetiracetam being considered as an alternative. ${ }^{17}$

Although multiple randomized controlled studies have compared the efficacy of different AED monotherapies, ${ }^{17}$ very few studies have examined their efficacy in elderly patients ( $\geq 60$ years) ${ }^{26-29}$ Moreover, these clinical trials have looked into the efficacy of different AEDs among older adults in terms of retention time as well as seizurefreedom over a 12-month period at most following the initiation of AED treatment. ${ }^{17,30,31}$ However, the efficacy of different AED monotherapies in terms of preventing seizure-related hospitalization, which is defined as inpatient hospital admissions due to uncontrolled seizures, 
following 12 months of stabilization with no incidence of seizure-related hospitalization has not been examined before in older adults with epilepsy. Therefore, the aim of this study was to compare the rates of seizure-related hospitalizations among older adults with epilepsy on levetiracetam, which is the most commonly used new AED among epileptic elderly patients in Saudi Arabia, compared to different AED monotherapies over a 24-month period following 12 months of treatment with no incidence of seizure-related hospitalization.

\section{Materials And Methods Study Design}

This study was a retrospective review of medical charts of older adults visiting outpatient neurology clinics at two tertiary care hospitals in Riyadh, Saudi Arabia. Patient medical charts were reviewed by two neurologists to confirm their diagnosis with epilepsy prior to their inclusion in the study. We identified 556 consecutive elderly epileptic patients who were at least 12 months free from a seizurerelated hospitalization, from patients seen in outpatient neurology clinics from Jan 2015 to Jan 2016. Retrospective data were collected from Jan 2014 to Jan 2018 using both paper and electronic patient medical records. Patients who were on more than one AED or not on a single AED for at least 36 months or who did not have complete data on prescription medications, and other comorbidities were excluded. Patients' age, gender, education level, nationality, marital status, type of seizure, number of prescription medications, and name and dosage of AED were collected. The burden of illness was assessed using the Charlson Comorbidity Index (CCI), which assigns weighted scores to 17 different medical conditions depending on the severity and nature of the medical condition that patient has; higher CCI scores are associated with worse rates of morbidity and mortality. ${ }^{32}$ The study was approved by the institutional review boards of King Saud University Medical City and King Faisal Specialist Hospital and Research Center in Riyadh, Saudi Arabia (project numbers E16-1933 and 2161160) were the data collection took place. The patient population in these two public tertiary care hospitals is mostly Saudi citizens who have been referred by the ministry of health. The study was granted a waiver of the consent form by the institutional review boards of the two hospitals since no personal identifiers (e.g., name, address, and national identification number) were collected. The ethical principles for medical research involving human subjects as stated in the declaration of Helsinki were adhered to.

\section{Participants}

Older adults aged 60 years or over with focal or generalized seizures and on a single AED were recruited to the study. Patients had to be on the same AED for at least 36 months and must not have had any seizure-related hospitalizations in the first 12 months of treatment prior to their follow-up for an additional 24 months. Cancer patients, and those with missing observations on prescription drugs and other comorbidities as well as those with no neurology outpatient clinic visits for regular check-up, and those with no electronic medical record were excluded from the study. Furthermore, patients who did not fill their medications on a regular basis were also excluded.

\section{Statistical Analysis}

The chi-square test or Fisher's exact test was used as appropriate to compare the percentages of categorical variables, such as gender, across the different AEDs. Analysis of variance (ANOVA) was used to compare the means of continuous variables across the patients on different AEDs. Multiple Poisson regression with robust error variance was used to estimate the relative risk of hospitalization for patients on different antiepileptic drugs controlling for age, gender, number of prescription medications, and Charlson Comorbidity Index (CCI) score. Furthermore, the dosage strengths of AEDs were controlled for using the interaction terms between the utilization of each AED and its dosage. The minimum sample size was estimated to be 68 patients based on $\alpha=0.05$, power of 0.8 , and medium effect size $\left(\mathrm{F}^{2}=0.15\right)$.

\section{Results}

Of 556 elderly epileptic patients who were identified between Jan 2015 and Jan2018, only 136 met the study's inclusion criteria and were included in the analysis, as is shown in Figure 1. The patients' sociodemographic and medical characteristics are summarized in Table 1. More than two-thirds of the patients (71\%) were on old AEDs, such as carbamazepine (32\%), phenytoin (23\%), and valproic acid (16\%), while approximately $29 \%$ of the patients were on levetiracetam. The mean ages of the patients on each AED were comparable, and their overall mean age was approximately 70 years. Most of the patients were married (84\%), with no formal education (57\%), male (54\%), and from Saudi Arabia (93\%). Approximately 


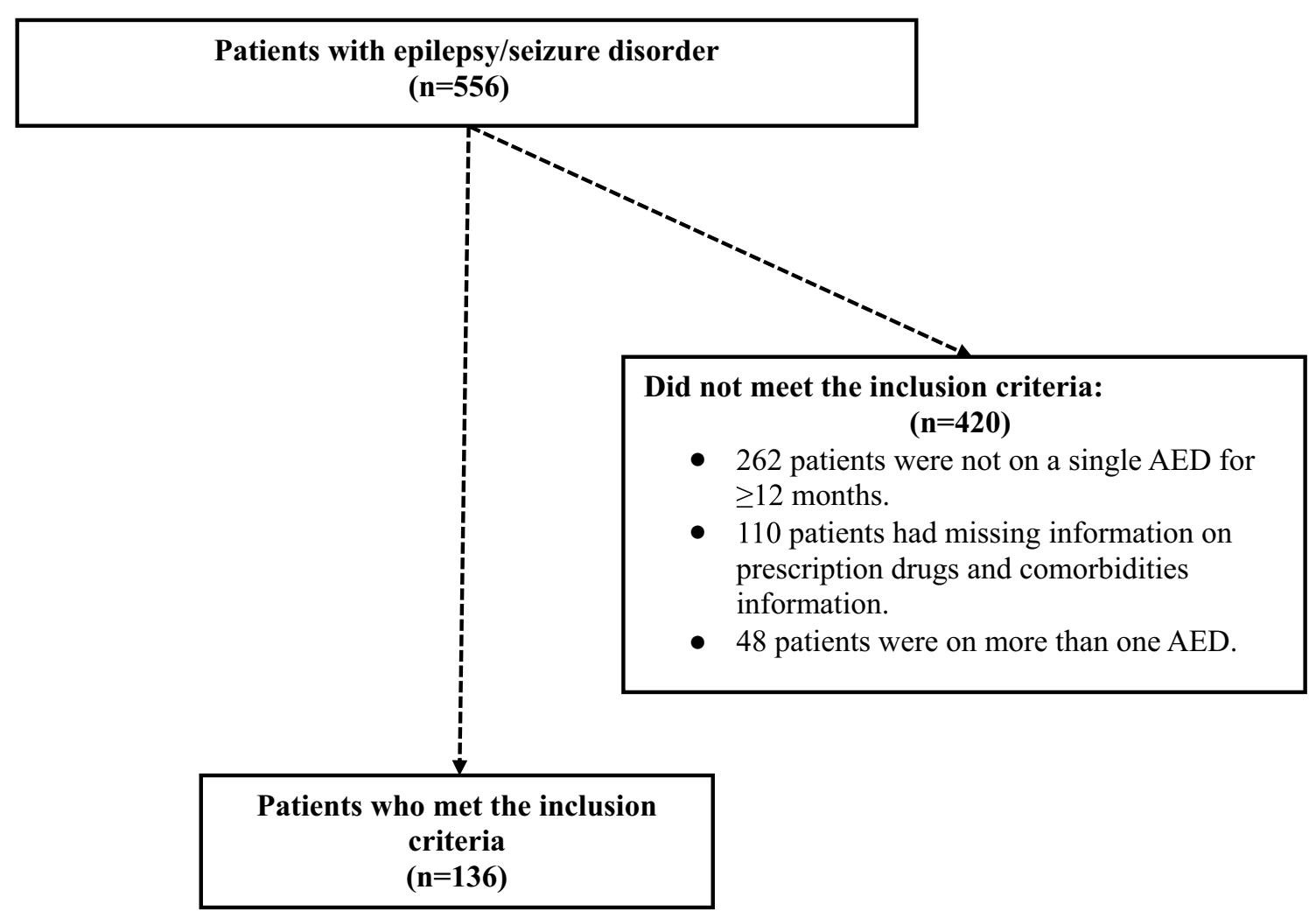

Figure I Patients' recruitment scheme.

$47 \%$ of the patients had generalized seizures, $26.47 \%$ had focal seizures, and $26.47 \%$ had unclassified seizures. The mean number of prescription medications and the CCI scores for the patients were approximately six and three, respectively. The mean dosages of patients on levetiracetam, carbamazepine, phenytoin, and valproic acid were approximately 1011, 456, 245, and $934 \mathrm{mg}$, respectively. Approximately $51 \%$ of the patients on levetiracetam, 39\% on carbamazepine, $36 \%$ on valproic acid, and $19 \%$ on phenytoin had an incidence of seizure-related hospitalization within the 24 months of follow-up as is shown in Figure 2. The utilization of levetiracetam was associated with almost a 3-fold higher risk of hospitalization due to seizure within the 24 months of follow-up ( $R R=2.76,95 \%$ $\mathrm{CI}=1.16-6.53, P=0.021)$ compared to other AEDs controlling for age, gender, education level, number of prescription medications, dosage strength, and CCI score, as shown in Table 2.

\section{Discussion}

The current study examined the rate of seizure-related hospitalizations among older adults with seizure disorders on levetiracetam monotherapy compared to different old
AED monotherapies, such as carbamazepine, phenytoin, and valproic acid, over a 24-month period. Although several randomized trials and observational studies have shown preferable therapeutic efficacy and favourable safety and drug interaction profiles of levetiracetam in the management of both focal and generalized seizures in comparison to different AED monotherapies, ${ }^{17}$ few of these studies were designed to examine the efficacy of levetiracetam among older adults. ${ }^{28,30,31}$ Furthermore, these studies have assessed the efficacy of different AED monotherapies using 12-month seizure-freedom rates $;{ }^{28,30,31}$ however, our current study examined the efficacy of levetiracetam and other AED monotherapies by comparing the rates of seizure-related hospitalizations between levetiracetam and other AED monotherapies for 24 months after 12 months of treatment stabilization with no incidence of seizure-related hospitalization. Interestingly, the findings of this study are at odds with the results of previous studies among older adults. ${ }^{30,31}$ Elderly patients on levetiracetam had a significantly higher risk of hospitalization due to seizures compared to phenytoin, valproic acid, and carbamazepine controlling for their age, gender, number of prescription medications, AED 
Table I Baseline Characteristics Of Patients

\begin{tabular}{|c|c|c|c|c|c|}
\hline \multirow[t]{2}{*}{ Characteristic } & \multicolumn{5}{|c|}{ Antiepileptic Drug (AED) } \\
\hline & $\begin{array}{l}\text { Levetiracetam } \\
(\mathrm{N}=39)\end{array}$ & $\begin{array}{l}\text { Carbamazepine } \\
(\mathrm{N}=44)\end{array}$ & $\begin{array}{l}\text { Phenytoin } \\
(\mathrm{N}=31)\end{array}$ & $\begin{array}{l}\text { Valproic Acid } \\
(\mathrm{N}=22)\end{array}$ & $\begin{array}{l}\text { Total } \\
(\mathrm{N}=136)\end{array}$ \\
\hline Age (years), mean \pm SD & $69.12 \pm 5.6$ & $69.02 \pm 7.75$ & $72.06 \pm 8.88$ & $69.36 \pm 9.13$ & $69.80 \pm 7.75$ \\
\hline $\begin{array}{l}\text { Gender, n (\%) } \\
\text { Male } \\
\text { Female }\end{array}$ & $\begin{array}{l}21(51.28) \\
18(46.15)\end{array}$ & $\begin{array}{l}23(52.27) \\
21(47.72)\end{array}$ & $\begin{array}{l}16(5 \mathrm{I} .6 \mathrm{I}) \\
15(48.38)\end{array}$ & $\begin{array}{l}14(63.63) \\
8(36.36)\end{array}$ & $\begin{array}{l}74(54.4 I) \\
62(45.59)\end{array}$ \\
\hline $\begin{array}{l}\text { Marital status, n (\%) } \\
\text { Married } \\
\text { Widowed } \\
\text { Divorced } \\
\text { Single }\end{array}$ & $\begin{array}{l}33(84.6 I) \\
6(15.38) \\
0(0.00 \%) \\
0(0.00 \%)\end{array}$ & $\begin{array}{l}40(90.9) \\
4(9.09) \\
0(0.00 \%) \\
0(0.00 \%)\end{array}$ & $\begin{array}{l}23(74.19) \\
2(6.45) \\
4(12.9) \\
2(6.45)\end{array}$ & $\begin{array}{l}18(8 \mid .8 I) \\
3(13.63) \\
0(0.00 \%) \\
I(4.54)\end{array}$ & $\begin{array}{l}114(83.82) \\
15(11.03) \\
4(2.94) \\
3(2.21)\end{array}$ \\
\hline $\begin{array}{l}\text { Nationality, n (\%) } \\
\text { Saudi } \\
\text { Non-Saudi }\end{array}$ & $\begin{array}{l}35(89.74) \\
4(10.25)\end{array}$ & $\begin{array}{l}41(93.18) \\
3(6.81)\end{array}$ & $\begin{array}{l}30(96.77) \\
\mathrm{I}(3.22)\end{array}$ & $\begin{array}{l}20(90.9) \\
2(9.09)\end{array}$ & $\begin{array}{l}126(92.65) \\
10(7.35)\end{array}$ \\
\hline $\begin{array}{l}\text { Education, n (\%) } \\
\text { No formal education } \\
\text { Elementary school } \\
\text { Intermediate school } \\
\text { High school } \\
\text { Associate degree } \\
\text { Bachelor degree }\end{array}$ & $\begin{array}{l}21(53.84) \\
6(15.38) \\
1(2.56) \\
3(7.69) \\
3(7.69) \\
5(12.82)\end{array}$ & $\begin{array}{l}27(6 I .36) \\
5(11.36) \\
3(6.8 I) \\
3(6.8 I) \\
4(9.09) \\
2(4.54)\end{array}$ & $\begin{array}{l}19(61.29) \\
5(16.12) \\
0(0.00 \%) \\
2(6.45) \\
2(6.45) \\
3(9.67)\end{array}$ & $\begin{array}{l}10(45.45) \\
2(9.09) \\
2(9.09) \\
0(0.00 \%) \\
2(9.09) \\
6(27.27)\end{array}$ & $\begin{array}{l}77(56.62) \\
18(13.24) \\
6(4.41) \\
8(5.88) \\
11(8.09) \\
16(11.76)\end{array}$ \\
\hline $\begin{array}{l}\text { Number of Prescription Medications, } \\
\text { mean } \pm \text { SD }\end{array}$ & $5.79 \pm 2.86$ & $5.38 \pm 3.13$ & $6.32 \pm 3.07$ & $6.31 \pm 3.06$ & $5.86 \pm 3.02$ \\
\hline $\mathrm{CCl}$, mean $\pm \mathrm{SD}$ & $3.35 \pm 2.09$ & $2.54 \pm 1.86$ & $3.7 \pm 2.9$ & $3.04 \pm 1.88$ & $3.12 \pm 2.23$ \\
\hline $\begin{array}{l}\text { Types of seizures, } \mathbf{n} \text { (\%) } \\
\text { Focal } \\
\text { Generalized } \\
\text { Unclassified }\end{array}$ & $\begin{array}{l}10(25.64) \\
17(43.58) \\
12(30.76)\end{array}$ & $\begin{array}{l}\text { I5 (34.09) } \\
\text { I8 (40.9) } \\
\text { II (25) }\end{array}$ & $\begin{array}{l}8(25.8) \\
13(41.9) \\
10(32.25)\end{array}$ & $\begin{array}{l}3(13.63) \\
16(72.72) \\
3(13.63)\end{array}$ & $\begin{array}{l}36(26.47) \\
64(47.06) \\
36(26.47)\end{array}$ \\
\hline Mean AED dosage in milligrams \pm SD & $1011.72 \pm 384.29$ & $465.22 \pm 224.32$ & $244.89 \pm 73.77$ & $933.87 \pm 395.26$ & - \\
\hline
\end{tabular}

Abbreviations: AED, antiepileptic drug, LEV, levetiracetam; CBZ, carbamazepine; PHT, phenytoin; VPA, valproic acid; CCI, Charlson comorbidity index.

dosage strength, burden of illness as measured by CCI, and education level. Patients on levetiracetam had the highest rate of seizure-related hospitalization, while patients on phenytoin had the lowest rate. Although phenytoin utilization for seizure disorders has been reduced over the last two decades largely because of its adverse effects profile, it appeared to perform better than most AEDs for both generalized and focal onset seizures. ${ }^{17}$ This study's results question the value of levetiracetam among elderly patients for controlling seizures and reducing the rate of seizure-related hospitalization, which is associated with significantly higher healthcare utilization costs $^{11}$ in the long term. Moreover, these findings may partially lend support to the authors' conclusions in the
Cochrane review on the efficacy of AED monotherapies, in which carbamazepine and sodium valproate are considered suitable as first-line treatments for focal onset and generalized tonic-clonic seizures, respectively, however it questions the suitability of levetiracetam as first-line treatment for the aforementioned types of seizures among elderly patients with epilepsy. ${ }^{17}$ Besides the higher likelihood of seizure-related hospitalization among elderly patients on levetiracetam, the number of prescription medications was associated with higher likelihood of seizurerelated hospitalization which is consistent with previously published studies that linked higher number of prescription medications among elderly patients with epilepsy to poor medication adherence and higher risk of hospitalization. ${ }^{33}$ 


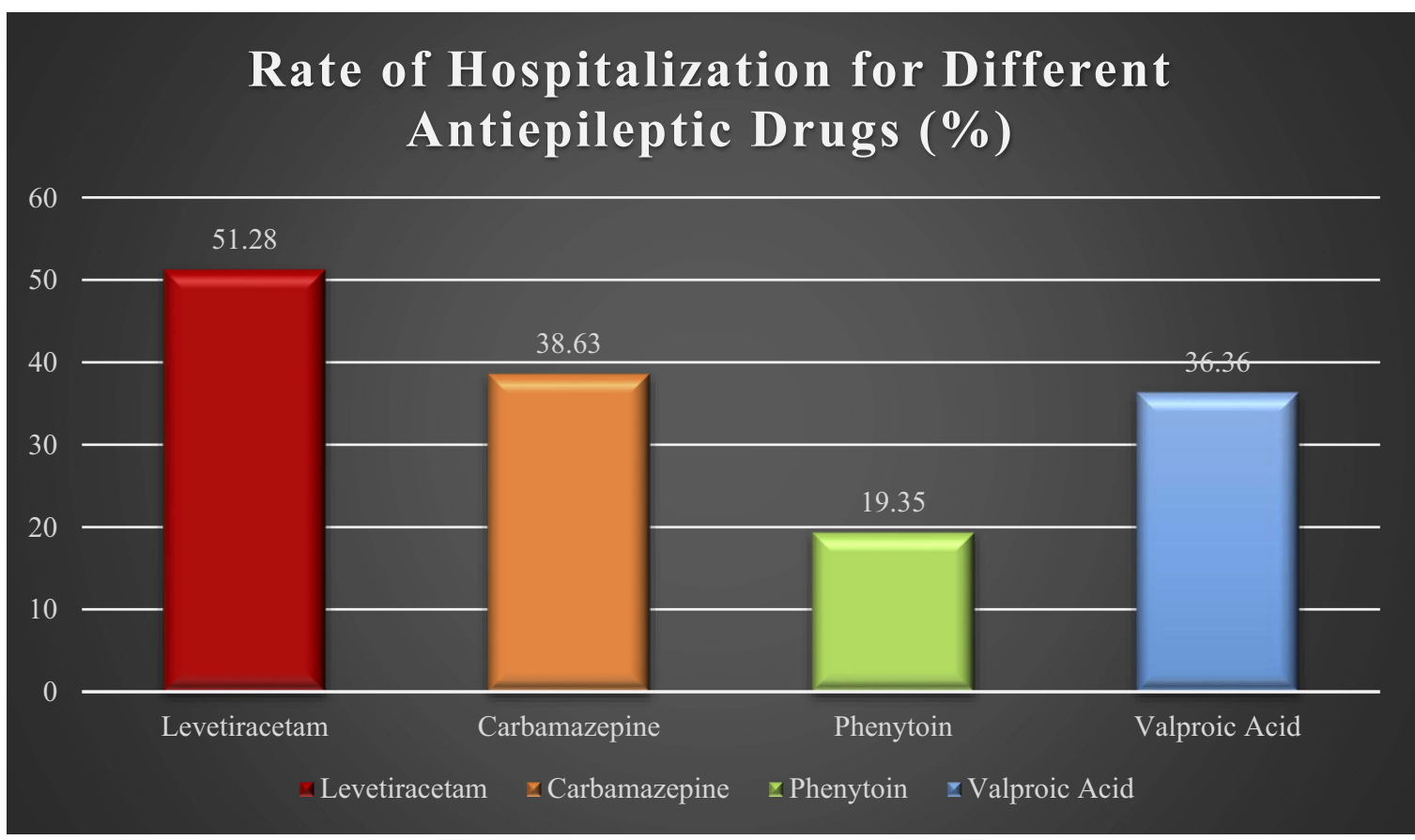

Figure 2 Rate of seizure-related hospitalization for different antiepileptic drugs.

Table 2 The Risk Of Hospitalization For Patients On Levetiracetam, Carbamazepine, Phenytoin, And Valproic Acid

\begin{tabular}{|l|l|l|}
\hline Variable & $\begin{array}{l}\text { Relative Risk (95\% } \\
\text { Confidence Interval) }\end{array}$ & P-value \\
\hline $\begin{array}{l}\text { Levetiracetam } \\
\text { utilization }^{\S}\end{array}$ & $2.76(1.16-6.53)$ & $\mathbf{0 . 0 2 I}$ \\
Education & $0.96(0.85-1.09)$ & 0.599 \\
CCl & $0.91(0.81-1.02)$ & 0.106 \\
Gender & $0.69(0.43-1.10)$ & 0.119 \\
Age & $0.99(0.96-1.03)$ & 0.961 \\
Number of prescription & $1.1(1.03-1.20)$ & $\mathbf{0 . 0 0 9}$ \\
medications & & \\
\hline
\end{tabular}

Notes: ${ }^{\S}$ The utilization of different antiepileptic drugs (AEDs) was adjusted for dosage strengths. The bold data signify statistical significant $(P<0.05)$.

Abbreviation: $\mathrm{CCl}$, Charlson comorbidity index.

Although this study has investigated the rate of seizurerelated hospitalization among older adults on levetiracetam monotherapy in comparison to old AEDs, such as phenytoin, carbamazepine, and valproic acid over a 24-month period, its findings have multiple limitations. First, the study design was a retrospective medical chart review, which has multiple limitations such as information bias. ${ }^{34}$ Furthermore, a significant number of patients were excluded due to missing information. Despite the fact that the patients in this study should not have any issues with their possession of AEDs given that prescription medications are dispensed for all patients without any charge in the medical centres in which the study took place, medication adherence was not controlled for. However, the authors have controlled for multiple variables that are believed to influence adherence, such as the number of prescription medications and the burden of illness as measured by the $\mathrm{CCI},{ }^{32}$ gender,35 and patients' level of education. ${ }^{36}$ Moreover, the study did not control for the frequency of seizures at baseline as well as the duration of illness which can influence the findings of this study. However, a 12-month period of stabilization on the same AED with no incidence of seizure-related hospitalization was chosen to reduce the impact of such confounding factors. Additionally, although the likelihood of patients being hospitalized in other hospitals due to seizures cannot be excluded, it is very unlikely given the structure of the public health system in Saudi Arabia in which patients can only be admitted in hospitals where their medical files are in. Emergency department (ED) visits were also not controlled for, however, all of the patients who were admitted were seen and evaluated in the ED before their admission. Finally, the study took place in only two tertiary care centers, which limits the generalizability of the study findings.

\section{Conclusion}

The management of epilepsy among older adults with levetiracetam may not be as effective as other old AEDs 
for ensuring seizure freedom in the long term, as the findings of this study suggest. Seizure-related hospitalizations are associated with immense direct medical costs and unfavourable clinical outcomes. Therefore, future studies should examine the rate of seizure-related hospitalizations among different AED monotherapies including levetiracetam on a large scale and with more robust research designs.

\section{Abbreviations}

AED, antiepileptic drug; CCI, Charlson comorbidity index; WHO, world health organization.

\section{Data Sharing Statement}

Study data are available from the authors upon request.

\section{Acknowledgments}

The authors thank Muhammad Alshehri and Saleh Alageel for their data collection efforts. The authors also acknowledge financial support from the Researchers Supporting Project number (RSP-2019/16), King Saud University, Riyadh, Saudi Arabia.

\section{Author Contributions}

All authors contributed to data analysis, drafting or revising the article, gave final approval for the version to be published, and agree to be accountable for all aspects of the work.

\section{Disclosure}

The authors report no conflicts of interest in this work.

\section{References}

1. Acharya JN, Acharya VJ. Epilepsy in the elderly: special considerations and challenges. Ann Indian Acad Neurol. 2014;17(Suppl 1):S18S26. doi:10.4103/0972-2327.128645

2. Picot MC, Baldy-Moulinier M, Daures JP, Dujols P, Crespel A. The prevalence of epilepsy and pharmacoresistant epilepsy in adults: a population-based study in a Western European country. Epilepsia. 2008;49(7):1230-1238. doi:10.1111/j.1528-1167.2008.01926.x

3. Brodie MJ, Elder AT, Kwan P. Epilepsy in later life. Lancet Neurol. 2009;8(11):1019-1030. doi:10.1016/S1474-4422(09)70240-6

4. Liu S, Yu W, Lü Y. The causes of new-onset epilepsy and seizures in the elderly. Neuropsychiatr Dis Treat. 2016;12:1425-1434. doi:10. 2147/NDT.S107905

5. Johnston A, Smith PEM. Epilepsy in the elderly. Expert Rev Neurother. 2010;10(12):1899-1910. doi:10.1586/ern.10.170

6. Brodie MJ, Kwan P. Epilepsy in elderly people. BMJ. 2005;331 (7528):1317-1322. doi:10.1136/bmj.331.7510.183

7. Murray CJ, Lopez AD; World Health Organization. Global Comparative Assessments in the Health Sector: Disease Burden, Expenditures and Intervention Packages. Geneva, (Switzerland): World Health Organization; 1994.
8. Ngugi AK, Bottomley C, Kleinschmidt I, Sander JW, Newton CR. Estimation of the burden of active and life-time epilepsy: a metaanalytic approach. Epilepsia. 2010;51(5):883-890. doi:10.1111/j.15 28-1167.2009.02481.x

9. Chen Z, Liew D, Kwan P. Excess mortality and hospitalized morbidity in newly treated epilepsy patients. Neurology. 2016;87(7):718 725. doi:10.1212/WNL.0000000000002984

10. Bautista RE, Glen ET, Wludyka PS, Shetty NK. Factors associated with utilization of healthcare resources among epilepsy patients. Epilepsy Res. 2008;79(2-3):120-129. doi:10.1016/j.eplepsyres.2008. 01.003

11. Ip Q, Malone DC, Chong J, Harris RB, Labiner DM. Economic impact of epilepsy and the cost of nonadherence to antiepileptic drugs in older medicare beneficiaries. Epilepsy Behav. 2018;80:208-214. doi:10.1016/j.yebeh.2018.01.009

12. Brodie MJ. Antiepileptic drug therapy the story so far. Seizure. 2010;19(10):650-655. doi:10.1016/j.seizure.2010.10.027

13. Kwan P, Brodie MJ. Phenobarbital for the treatment of epilepsy in the 21st century: a critical review. Epilepsia. 2004;45(9):1141-1149. doi:10.1111/epi.2004.45.issue-9

14. Kaniwa N, Saito Y. The risk of cutaneous adverse reactions among patients with the HLA-A* 31:01 allele who are given carbamazepine, oxcarbazepine or eslicarbazepine: a perspective review. Ther $A d v$ Drug Saf. 2013;4(6):246-253. doi:10.1177/2042098613499791

15. Lee SK. Old versus new: why do we need new antiepileptic drugs? $J$ Epilepsy Res. 2014;4(2):39-44. doi:10.14581/jer.14010

16. French JA, Gazzola DM. New generation antiepileptic drugs: what do they offer in terms of improved tolerability and safety? Ther $A d v$ Drug Saf. 2011;2(4):141-158. doi:10.1177/2042098611411127

17. Nevitt SJ, Sudell M, Weston J, Smith CT, Marson AG. Antiepileptic drug monotherapy for epilepsy: a network meta-analysis of individual participant data. Cochrane Database Syst Rev. 2017;6:CD011412.

18. Glauser T, Ben-Menachem E, Bourgeois B, et al. Updated ILAE evidence review of antiepileptic drug efficacy and effectiveness as initial monotherapy for epileptic seizures and syndromes. Epilepsia. 2013;54(3):551-563. doi:10.1111/epi.12074

19. Berg AT, Berkovic SF, Brodie MJ, et al. Revised terminology and concepts for organization of seizures and epilepsies: report of the ILAE commission on classification and terminology, 2005-2009. Epilepsia. 2010;51(4):676-685. doi:10.1111/j.1528-1167.2010.02522.x

20. Brodie MJ, Perucca E, Ryvlin P, Ben-Menachem E, Meencke HJ. Comparison of levetiracetam and controlled-release carbamazepine in newly diagnosed epilepsy. Neurology. 2007;68(6):402-408. doi:10. 1212/01.wnl.0000252941.50833.4a

21. Consoli D, Bosco D, Postorino P, et al. Levetiracetam versus carbamazepine in patients with late poststroke seizures: a multicenter prospective randomized open-label study (EpIC Project). Cerebrovasc Dis. 2012;34(4):282-289. doi:10.1159/000342669

22. Hakami T, O'Brien TJ, Petty SJ, et al. Monotherapy with levetiracetam versus older AEDs: a randomized comparative trial of effects on bone health. Calcif Tissue Int. 2016;98(6):556-565. doi:10.1007/ s00223-016-0109-7

23. Almalag HM, Alzahrani H, Al-Hussain F, et al. The impact of old versus new antiepileptic drugs on costs and patient reported outcomes among older adults. Geriatr Nurs. 2018;39(6):669-675. doi:10.1016/ j.gerinurse.2017.12.012

24. Marson AG, Al-Kharusi AM, Alwaidh M, et al. The SANAD study of effectiveness of carbamazepine, gabapentin, lamotrigine, oxcarbazepine, or topiramate for treatment of partial epilepsy: an unblinded randomised controlled trial. Lancet. 2007;369(9566):1000-1015. doi:10.1016/S0140-6736(07)60460-7

25. Marson AG, Al-Kharusi AM, Alwaidh M, et al. The SANAD study of effectiveness of valproate, lamotrigine, or topiramate for generalised and unclassifiable epilepsy: an unblinded randomised controlled trial. Lancet. 2007;369(9566):1016-1026. doi:10.1016/S0140-6736 (07)60461-9 
26. Brodie MJ, Overstall PW, Giorgi L. Multicentre, double-blind, randomised comparison between lamotrigine and carbamazepine in elderly patients with newly diagnosed epilepsy. The UK lamotrigine elderly study group. Epilepsy Res. 1999;37(1):81-87. doi:10.1016/ S0920-1211(99)00039-X

27. Saetre E, Perucca E, Isojarvi J, Gjerstad L. An international multicenter randomized double-blind controlled trial of lamotrigine and sustained-release carbamazepine in the treatment of newly diagnosed epilepsy in the elderly. Epilepsia. 2007;48(7):1292-1302. doi:10.11 11/j.1528-1167.2007.01128.x

28. Motamedi M, Ghini MR, Etemadi P, Ramim T. Levetiracetam and lamotrigine in old aged onset of epilepsy: a randomized double-blind clinical trial. Tehran Univ Med J. 2013;71(9):568-576.

29. Rowan AJ, Ramsay RE, Collins JF, et al. New onset geriatric epilepsy: a randomized study of gabapentin, lamotrigine, and carbamazepine. Neurology. 2005;64(11):1868-1873. doi:10.1212/01.WNL.00 00167384.68207.3E

30. Werhahn KJ, Trinka E, Dobesberger J, et al. A randomized, doubleblind comparison of antiepileptic drug treatment in the elderly with new-onset focal epilepsy. Epilepsia. 2015;56(3):450-459. doi:10.11 11/epi.12926
31. Arif H, Buchsbaum R, Pierro J, et al. Comparative effectiveness of 10 antiepileptic drugs in older adults with epilepsy. Arch Neurol. 2010;67(4):408-415. doi:10.1001/archneurol.2010.49

32. Charlson ME, Pompei P, Ales KL, MacKenzie CR. A new method of classifying prognostic comorbidity in longitudinal studies: development and validation. J Chronic Dis. 1987;40(5):373-383. doi:10.10 16/0021-9681(87)90171-8

33. Zelko E, Klemenc-Ketis Z, Tusek-Bunc K. Medication adherence in elderly with polypharmacy living at home: a systematic review of existing studies. Mater Sociomed. 2016;28(2):129-132. doi:10.5455/msm.

34. Vassar M, Holzmann M. The retrospective chart review: important methodological considerations. J Educ Eval Health Prof. 2013;10:12. doi:10.3352/jeehp.2013.10.12

35. Zafar A, Shahid R, Nazish S, et al. Nonadherence to antiepileptic medications: still a major issue to be addressed in the management of epilepsy. J Neurosci Rural Pract. 2019;10(1):106-112. doi:10.4103/ jnrp.jnrp_136_18

36. Pandey A, Suskin N, Patel T, Choudhry N. Lower educational levels may be an important determinant of adherence to evidenced-based therapies in post-MI patients. J Am Coll Cardiol. 2017;69(11 Supplement):1847. doi:10.1016/j.jacc.2016.11.026

\section{Publish your work in this journal}

Neuropsychiatric Disease and Treatment is an international, peerreviewed journal of clinical therapeutics and pharmacology focusing on concise rapid reporting of clinical or pre-clinical studies on a range of neuropsychiatric and neurological disorders. This journal is indexed on PubMed Central, the 'PsycINFO' database and CAS, and is the official journal of The International Neuropsychiatric Association (INA). The manuscript management system is completely online and includes a very quick and fair peer-review system, which is all easy to use. Visit http://www.dovepress.com/testimonials.php to read real quotes from published authors. 